\title{
DESIGN OF COMPRESSOR ENDWALL VELOCITY TRIANGLES
}

\author{
Kiran Auchoybur* and Robert J. Miller \\ Whittle Laboratory, University of Cambridge \\ United Kingdom \\ e-mail:ka268@cam.ac.uk
}

\begin{abstract}
The operating range of a compressor is usually limited by the rapid growth of $3 D$ separations in the endwall flow region. By contrast, the freestream region is not usually close to its diffusion limit and has little effect on overall range. In light of these two distinct flow regions, this paper considers how velocity triangles in the endwall region should be designed to give a more balanced spanwise failure across the span of a blade row.
\end{abstract}

In the first part of the paper, the sensitivity of $3 D$ separations in a single blade row to variations in realistic multi-stage inlet conditions and endwall geometry is investigated. It is shown that a blade's $3 D$ separation size is largely controlled by the dynamic pressure within the incoming endwall 'repeating stage' boundary layer and not the detailed local geometry within the blade row.

In the second part of the paper the traditional design process is 'flipped'. Instead of redesigning a blade's endwall geometry to cope with a particular inlet profile into the blade row, the endwall region is redesigned in the multi-stage environment to 'tailor' the inlet profile into downstream blade rows, giving the designer a new extra degree of freedom. This extra degree of freedom is exploited to balance freestream and endwall operating range, resulting in a compressor having an increased operating range of $\sim 20 \%$. If this increased operating range is traded with reduced blade count, it is shown that a design efficiency improvement of $\sim 0.5 \%$ can be unlocked.

\section{INTRODUCTION}

A typical compressor design process involves initially using a through-flow method to design the blade velocity triangles across the span. The through-flow design often makes use of extensive experimental rig data to determine the radial profiles. These radial profiles are then locked and 3D CFD is used to improve the endwall design, both by introducing lean and sweep and by fine tuning blade angles. The aim of these traditional design processes is to ensure that each blade row meets its required operating range with a specified inlet profile, with minimum loss. Inherent in this design process is the idea of redesigning a blade's endwall region to achieve the required range with a specified inlet profile.

In this paper this design process is 'flipped'. Instead of fixing the inlet profile early in the design process, the blade endwall design is used to 'tailor' the inlet profile. This tailored profile is achieved by designing in the repeating stage environment. This method is shown to give the designer an added degree of freedom and opens up the possibility of balancing the operating range of freestream and endwall regions of the flow, a freedom not open to designers using traditional design processes. A more balance spanwise failure extends the overall operating range, which can in turn be traded to improve the design performance of the compressor.

An example of this new design philosophy is shown in Figure 1. The CFD is undertaken in a repeating stage environment, with an ideal shroud endwall topology. Details of the case are given later in this paper. The LHS plot shows a blade designed in a conventional design process. In this case the blade inlet and exit metal angle profiles are set by a through flow. 3D CFD is then used to fine tune blade angles and introduce lean and sweep. The RHS plot shows the new design philosophy outlined in this paper. The design is undertaken in the repeating stage environment. In this case the designer has designed the velocity triangle in the endwall region to raise the

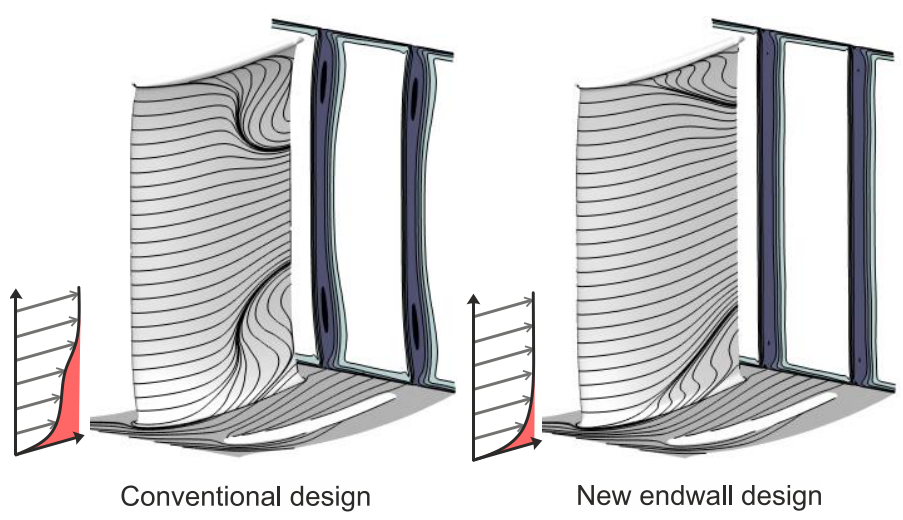

Figure 1 Stator 3D flow field in the repeating stage. LHS conventional design, RHS Design used to tailor inlet endwall region. (Each at same off-design flow coefficient) 
flow coefficient locally. This extra degree of freedom allows the designer to achieve a more balanced design across the blade span, with the wake being more uniform radially.

In multistage design, the idea of specifying an inlet profile and meeting a range requirement encourages a very 'blade centric' view of endwall design. In this view the inlet profiles set the radial profiles of de Haller number, or static pressure rise coefficient, which in turn are inputs to the endwall design process. Of course if these requirements prove impossible to meet, the designer always has the freedom to go back to the through-flow and redistribute loading between stages or increase stage number. However, this design process encourages designers to change endwall blade geometry with the aim of improving the endwall flow in that particular blade row rather than improving the endwall flow in the whole spool.

This 'blade centric' view of endwall design encourages the development of technologies which reduce the de Haller number or increase the static pressure rise coefficient at which the endwall fails. Examples of such technologies include lean, sweep and endwall contouring. These technologies, such as Gallimore et al. [1] and more recently Taylor and Miller [2], allow the endwall and trailing edge separations to be balanced in design to achieve an increased endwall failure static pressure rise coefficient. However effective these technologies are, they are all aimed at recovering a blade row from the detrimental effect of a low dynamic pressure (or dynamic head) at its inlet in the endwall region. Instead this paper argues that in the multistage environment the designer's main aim should be to design a blade which raises the endwall dynamic pressure into downstream blade rows.

Little published literature has attempted to use the design of velocity triangles in the endwall region to tailor the endwall flow. One exception is the NASA/GE $\mathrm{E}^{3}$ compressor study [3] which involved learning from experience gained on the GE Low Speed Research Compressor [4]. Here the radial profiles were experimentally measured in a multistage environment, and then used as inputs to the design process. The design process was then repeated leading to a new design with the aim of reducing endwall loss. This process captures two of the important features of design process described in this paper: First it involves testing the success or failure of a design in a repeating stage environment, not in a cascade or single-stage. Second, it involves designing an endwall, measuring the resulting endwall flow experimentally and then repeating the design process with the new endwall flow profile as an input. This captures the same key elements of the design philosophy in this paper. Unfortunately, the overhead of doing such work experimentally meant that in the $\mathrm{E}^{3}$ research, the true impact of endwall design on the endwall flow was difficult to identify.

The work in this paper starts by undertaking a sensitivity analysis to determine the dominant factors affecting the size of 3D separations within an embedded stage blade row. This understanding is then used to develop a new design philosophy for multistage compressor endwall design. Lastly, the method is demonstrated on a variety of cases.

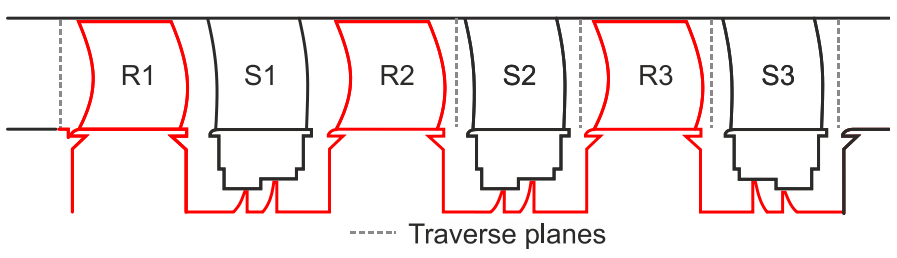

Figure 2 SMURF multistage low speed compressor

\section{METHODOLOGY}

\section{Experimental}

Two experimental rigs are used in this paper. The first, SMURF [5] shown in Figure 2, is a low-speed multistage compressor, representative of a modern high pressure compressor. Each stage has identical geometry, 1\% span stator shroud clearances and $1.75 \%$ span rotor tip clearance. The average stage Reynolds number is $\sim 5 \times 10^{5}$, based on chord, with blade aspect ratios of $\sim 1$, and stage reaction based on mid-span of $65 \%$. The second experimental rig used towards the end of the paper is the Gibbons single stage compressor, documented in Taylor and Miller [2]. This stage is a scale of the SMURF geometry, but with a fully sealed under stator platform.

\section{Computational}

The CFD results presented in this paper are computed by Rolls-Royce's in-house solver Hydra [6], operated in steady RANS mode with mixing planes and Menter's k- $\omega$ SST turbulence model [7]. PADRAM [8] is used in the mesh generation. The main gas path meshes are multi-block structured $\mathrm{O}-\mathrm{H}$ grid topologies with a $\mathrm{y}+\sim 1$ on all viscous surfaces. Shroud cavity wells are fully modelled using an unstructured mesh. Transition regions on the suction surface are imposed for studies on the SMURF rig. However, given the fairly weak influence on the overall flow structures observed, a fully turbulent approach is used for the case studies section of the paper.

\section{Linear repeating stage CFD}

An important aspect of this work is to consider the impact of blade design choices on the repeating stage endwall boundary layer. Therefore, in the second part of the paper a 'Linear Repeating Stage' approach is adopted. This approach was developed by McKenzie [9] and first implemented computationally by To \& Miller [10]. Smith [11] showed the repeating stage condition, where stage velocity profiles repeat, begins after three/four stages in well-matched compressors..

The linear repeating stage approach involves four elements: First the hub-to-tip ratio of the stage is set to one, which effectively turns each blade row into a linear cascade, but with rotor-stator coupling. This simplifies the analysis of the $3 \mathrm{D}$ flow field by removing inviscid spanwise variations in the stage velocity triangle.

Second, to achieve the repeating stage condition, a three bladerow model (rotor, stator, rotor) is run to convergence, then 


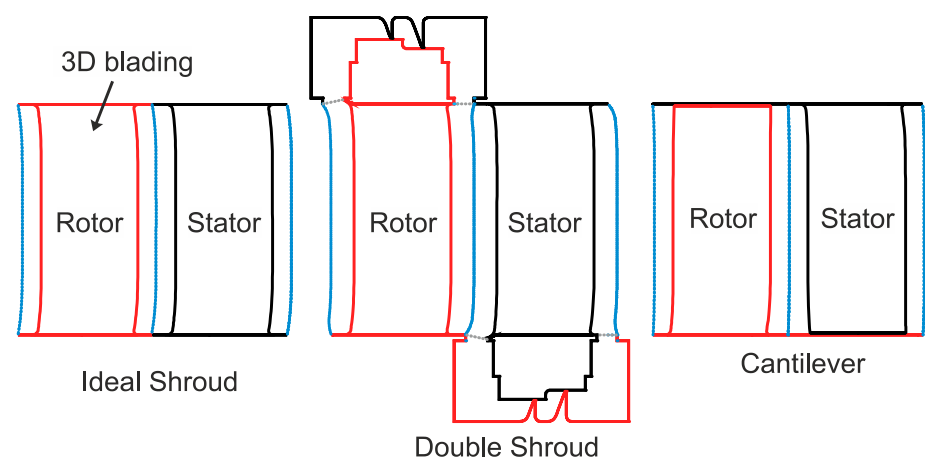

Figure 3 Endwall geometry configurations considered the stator exit boundary condition is used as the inlet condition for the next solution. This is repeated ten times, with the tenth stage considered the repeating stage solution.

Third, the flow is all considered incompressible so that endwalls remain parallel. Finally, a 50\% reaction stage is chosen to evenly balance the aerodynamic diffusion between rotor and stator. This also means that at any particular stream height, the blade relative exit flow angle of rotor and stator, $\beta_{2}$ and $\alpha_{2}$ respectively, are identical.

\section{Case Study Designs}

In the middle of the paper, three design case studies, shown in Figure 3, will be undertaken. These include ideal shroud, real shroud and cantilever. Each has anti-symmetric endwalls so that the rotor and stator have the same endwall geometry. This was deliberately chosen so that the behaviour of shrouds and cantilevers could be studied independently. The clearances used for both cantilevered and shrouded cases are set to $1 \%$ of the aerofoil chord length. The ideal shroud has zero clearance and plane endwalls.

The blade geometry used in the case studies is a controlled diffusion aerofoil, at the same design work and flow coefficient representative of modern HP compressors. At this design condition, the rotor and stator blades are re-cambered to position the stagnation streamline on the nose of the blade in the free-stream and part way into the endwall region, based on the repeating stage profile. The chord length is uniform across the span. To aid splitting freestream and endwall flows, a blade aspect ratio of two is used.

\section{SENSITIVITY OF ENDWALL 3D SEPARATIONS}

This paper is based on the idea that that a blade's endwall 3D separation size is primarily a function of the deficit in the dynamic pressure in the incoming endwall boundary layer. At the start of this work we did not fully appreciate this fact, with our understanding developing through a series of experimental tests and computational predictions which will be described briefly in this section.

The geometry studied is the second stage stator in the SMURF multi-stage low speed compressor. In the study the computation of the stator was run with its experimentally measured inlet condition. The downstream compressor stage was included in the solutions. A number of flow coefficients were studied but only one will be discussed in this section: $\phi / \phi_{r e}=0.85$. The experimental inlet profile and the stator exit loss coefficient for both the experimental and computational cases are shown in in Figure 4. The computation can be seen to accurately predict the balance of hub and casing separations. This accuracy of prediction is unsurprising for cases where the experimentally measured inlet profile is used at blade inlet. The same accuracy would not be achieved two or more blade rows downstream of the experimentally measured inlet profile.

To investigate the sensitivity of the stator endwall 3D separation, a number of simulations were undertaken. First the stator endwall geometry was altered. Three initial computational cases were performed: (i) Leakage gap reduced to $0 \%$ chord, (ii) The real shroud replaced with an ideal shroud and (iii) The stator endwall made inviscid. In addition, an experimental test was performed on the SMURF rig where roughness was added to the stator endwall platform. In all cases very little change to the stator endwall $3 \mathrm{D}$ separation structure was observed. An example of this unexpected behaviour can be seen by comparing the LHS and middle of Figure 5. The case on the LHS shows the baseline solution complete with all endwall geometry features. The case in the middle shows the solution without a shroud and an inviscid endwall. It should be noted that no geometry changes were made to the blade surface. Goodhand and Miller [12] showed that this can potentially have a significant impact on the size of 3D separations.

In the next set of studies the stator inlet dynamic pressure was changed in the endwall region. Two extra computational cases were performed: (i) An idealised inviscid profile introduced to replace the 'inner highly skewed hub endwall boundary layer' (0-5\% span) and (ii) an idealised inviscid profile introduced in the 'broader endwall flow' regions (5-40\% span in the hub region and $60-100 \%$ span in the casing region). The decision to differentiate between these two regions of the endwall boundary layer was made because the 'inner highly skewed boundary layer' is local to that blade row and is the result of the change in reference frame while the 'broader endwall' region develops over multiple stages and is due to the so called repeating stage effect. The results of the computation were once again unexpected. Changing the 'inner highly skewed boundary layer' region was found to have very little effect on the stator endwall 3D separation structure. While
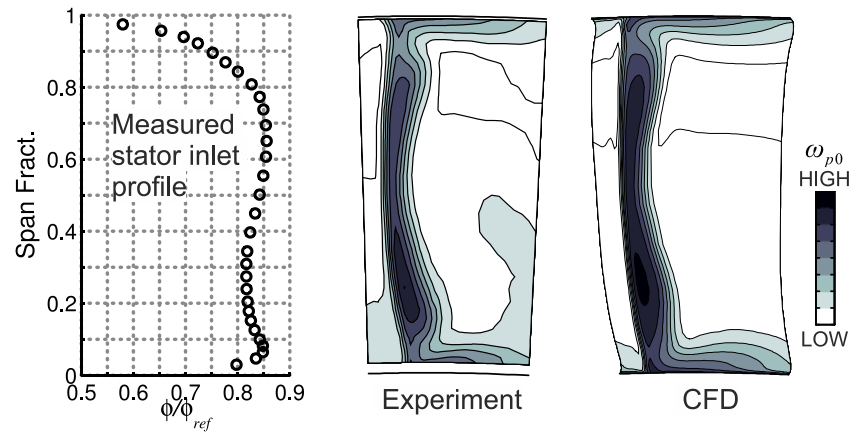

Figure 4 SMURF stator 2 experiment vs CFD model loss contours (CFD uses LHS measured profile), $\phi / \phi_{\text {ref }}=0.85$ 


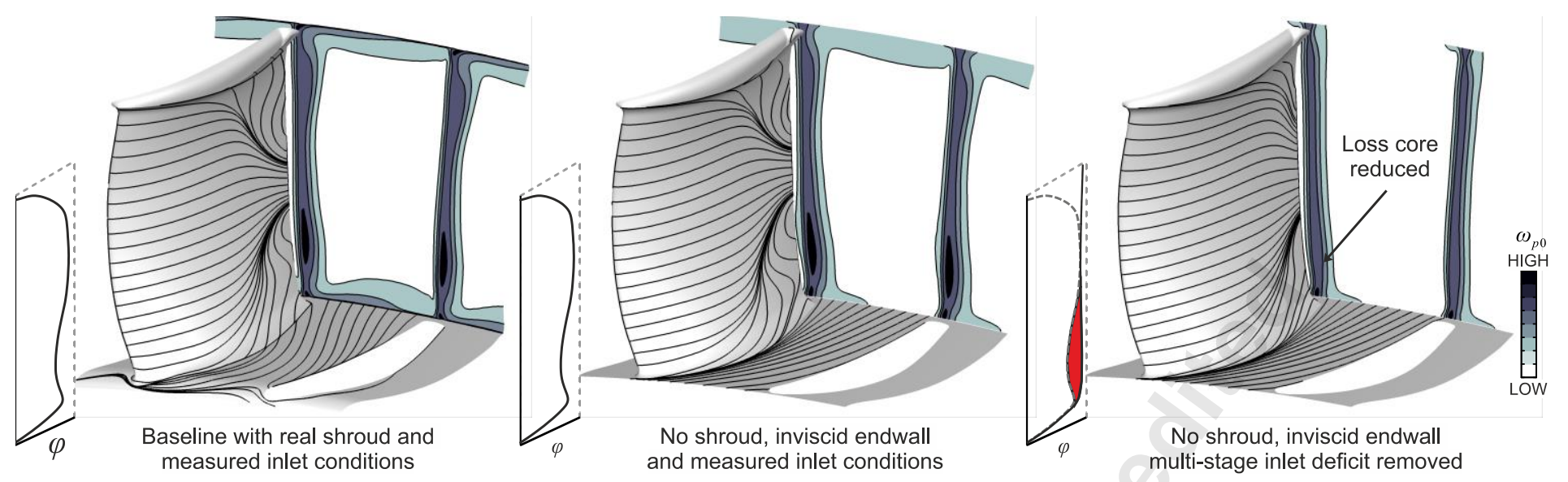

Figure $5 \mathrm{Effect}$ of blade row inlet conditions and local endwall geometry on endwall 3D separation size $\left(\phi_{\text {mid }} / \phi_{\text {ref }}=0.92\right)$

changing the radial flow profile in the 'broader endwall' region was found to have a much larger effect. The effect can be seen by comparing the LHS and RHS of Figure 5. The case on the LHS shows the baseline solution whilst the RHS shows the case with an inviscid profile added in the broader endwall region.

The observation that the endwall $3 \mathrm{D}$ separation structure is more sensitive to the 'broader endwall' region inlet profile can be explained by two reasons. Firstly, this region of flow possesses a much larger deficit in incoming dynamic pressure than the 'inner highly skewed boundary layer'. Secondly, the inner skewed boundary layer constitutes a much smaller proportion of the overall mass flux than the broader endwall region. This sensitivity study indicates that if a designer wishes to significantly reduce the size of $3 \mathrm{D}$ separations within a blade row, then their primary aim should be to reduce the dynamic pressure deficit associated with the repeating stage boundary layer which develops in multistage compressors.

\section{NEW DESIGN PHILOSOPHY}

A new design philosophy will now be developed with the aim of rebalancing the range of the endwall and freestream regions. The design philosophy involves using the blade's velocity triangle in the endwall region to 'tailor' the endwall boundary layer leaving the blade row. Because the stage being studied is operated as a repeating stage, this will be shown to allow the flow coefficient in the endwall region to be 'tailored'.

\section{Parallel compressor model}

The design philosophy is based on a parallel compressor model. The model is not aimed as a predictive tool but instead to allow low-order understanding to be extracted from CFD solutions so that redesign can be undertaken. This methodology allows the designer to extract velocity triangles and one dimensional performance parameters from the freestream and endwall regions.

The model decomposes the flow into two parallel compressors, a freestream compressor and an endwall compressor. A schematic showing the two compressors is shown in Figure 6. The freestream and endwall regions are defined by a fixed mass flow ratio. For this stage under study, which has an aspect ratio of two, the endwall region is set as 1$25 \%$ and $75-99 \%$ mass flux. The freestream region is set as 25 $75 \%$ mass flux.

As the compressor is throttled the mass flow ratio is held constant and the area ratio between the two compressors is allowed to vary. This results in the fraction of passage height filled by the endwall flow rising as the compressor is throttled. This behaviour was found to accurately simulate the real behaviour observed in the compressor.

Figure 7 shows the two decomposed compressor characteristics extracted from a CFD solution. The solution is for a linear repeating stage designed with a uniform velocity triangle across the blade span and with an ideal endwall shroud. The LHS of Figure 7 shows the pressure rise characteristic and the RHS shows the loading characteristic.

The first thing to note in Figure 7 is that the freestream and endwall operate at the same total pressure rise coefficient (LHS of the figure). This is because in the repeating stage with incompressible flow, the static and total pressure rise at all spanwise locations are identical, as explained in Smith [11]. An important reason for this is that the spanwise static pressure rise is set by the bulk flow or in this case, the freestream region.

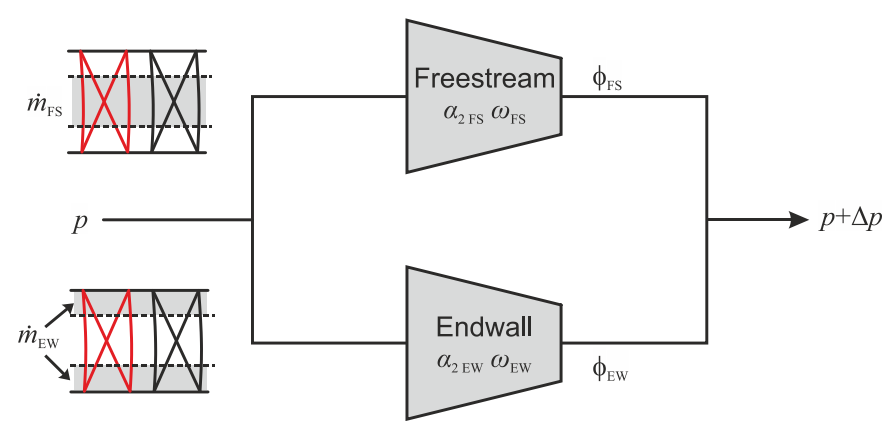

Figure 6 Parallel compressor model of freestream and endwall regions 

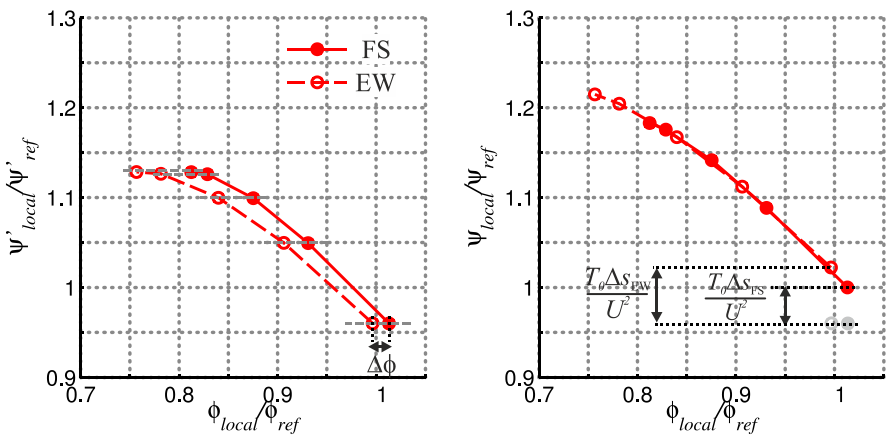

Figure 7 Total pressure rise coefficient (LHS) and loading (RHS) characteristics for endwall and freestream regions

The second thing to note in Figure 7 is that the loading characteristics of the freestream and endwall (RHS of the figure) are on top of each other. This is because the blade velocity triangle is uniform across the span and the deviation in the endwall and freestream only differs by $0.2^{\circ}$.

The relationship between the total pressure rise coefficient and the loading characteristic can be understood by considering the enthalpy form of the "Tds" equation for an incompressible flow, divided by blade speed squared.

$$
\frac{\Delta h_{0}}{U^{2}}=\frac{\Delta p_{0}}{\rho U^{2}}+\frac{T_{0} \Delta s}{U^{2}}
$$

This can be written as

$$
\psi=\psi^{\prime}+\frac{T_{0} \Delta s}{U^{2}}
$$

This shows that the loading characteristic is simply achieved by shifting the pressure rise characteristic vertically by a term proportional to the loss.

Figure 7 shows that the difference in the flow coefficient in the freestream and endwall compressors, $\Delta \phi$, is fixed by the ratio of the freestream to endwall loss. As this ratio is largely fixed by the choice of seal clearance and the choice of endwall geometry topology (i.e. shroud or cantilever) it implies that once these have been set then the endwall deficit in flow coefficient is fixed.

\section{Design of endwall velocity triangle}

The only way to significantly change a compressor's design flow coefficient is to change its velocity triangle. If the parallel compressor model is correct, this implies that changing the flow coefficient in the endwall region can only be achieved by changing the velocity triangle in the endwall region.

Four redesigns of endwall velocity triangle were undertaken: Increased and reduced inlet metal angle by $2^{\circ}$, and increased and reduced exit metal angle by $2^{\circ}$. The perturbations in metal angle were blended into the freestream value by a distance of $50 \%$ chord from the endwall. When designs were found to alter the difference the overall flow coefficient of the

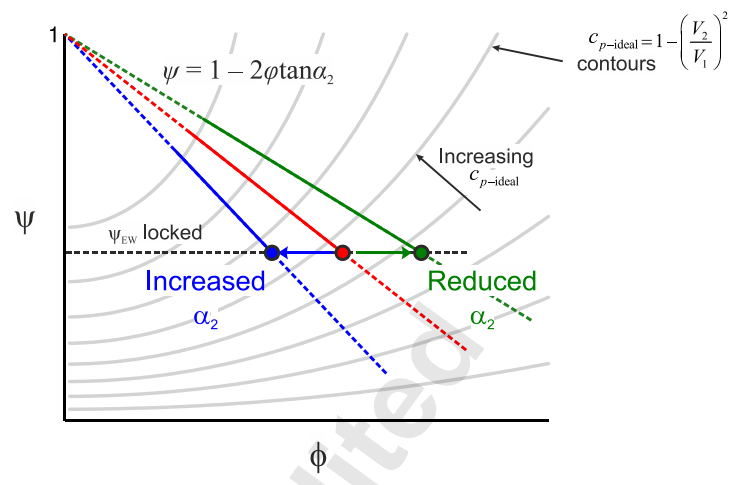

Figure 8 Ideal characteristics for changing exit flow angle

compressor, the freestream velocity triangle was redesigned so that the overall design flow coefficient and pressure rise of the compressor remained unchanged.

Varying inlet metal angle was found to have little effect on performance. This can be explained by Wadia and Beacher [13] and Cumpsty's discussion [14]. In the endwall region the pressure field is largely imposed by the freestream flow and thus independent of locally high levels of endwall skew.

Varying the exit metal angle was found to have a large effect on the endwall flow coefficient. This can be understood by considering Euler's work equation for a 50\% reaction stage:

$$
\psi=1-2 \phi \tan \alpha_{2}
$$

where $\alpha_{2}$ is the exit flow angle of both rotor and stator rows in the blade relative frame. Figure 8 shows equation 3 plotted for constant deviation. By ensuring the freestream pressure rise for all designs remains unchanged, changing the exit angle in the endwall region does not change the pressure rise imposed onto the endwall. The endwall loss is also relatively constant and so the endwall flow coefficient moves along a horizontal line. Reducing $\alpha_{2}$ increases the endwall flow coefficient and increasing $\alpha_{2}$ reduces the endwall flow coefficient.

Figure 8 also shows contours of ideal static pressure rise coefficient, $c_{p \text {-ideal }}$. Increasing the endwall flow coefficient by reducing $\alpha_{2}$ moves the endwall to a region of lower $c_{p}$.

To confirm this behaviour, the two compressors with increased and reduced endwall $\alpha_{2}$ were run across their operating characteristics and the results decomposed using the parallel compressor model. The endwall loading characteristics are shown in Figure 9. The figure shows that changing blade exit flow angle $\alpha_{2}$ is a powerful way of changing the difference between the freestream and endwall flow coefficient, $\Delta \phi$.

The effect of the blade exit flow angle on the spanwise distribution of flow coefficient, local pressure rise coefficient and loss is shown in Figure 10, for an off-design operating point. The local pressure rise coefficient and loss will be discussed in the next section. Reducing the exit flow angle can be seen to have a powerful effect on raising the flow coefficient across the whole the endwall region. 


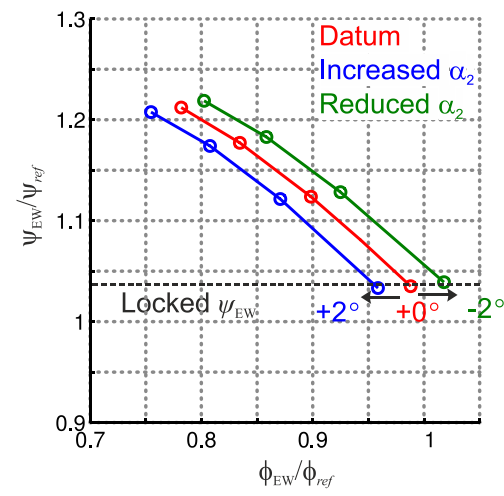

Figure 9 Movement of endwall loading characteristic with changing exit angle $\left( \pm 2^{\circ}\right)$, extracted from CFD

\section{Balancing endwall and freestream range}

The ability to 'tailor' endwall flow coefficient raises the question of what value of endwall flow coefficient a designer should select. A rational choice would be to base their choice on the balance of endwall and freestream loss.

During this study one of the most interesting findings, pertinent to the current question, is that for small changes in exit metal angle (and similar levels of 3D lean) a universal curve, a 'loss characteristic', describing the variation of endwall loss with local pressure rise coefficient can be defined. This is achieved by defining the local pressure rise coefficient

$$
c_{p}=\frac{\Delta p}{1 / 2 \rho V_{\text {local }}^{2}}
$$

Where $V_{\text {local }}$ is the blade inlet velocity in the blade relative frame. The velocity is derived by mass averaging in the region of interest (endwall or freestream). The denominator in this expression is the so called 'dynamic pressure'.

The 'loss characteristic', the endwall loss coefficient plotted against the local pressure rise coefficient is shown in Figure 11. The LHS shows the local pressure rise coefficient calculated using the freestream dynamic pressure. The RHS shows the local pressure rise coefficient calculated using the local endwall
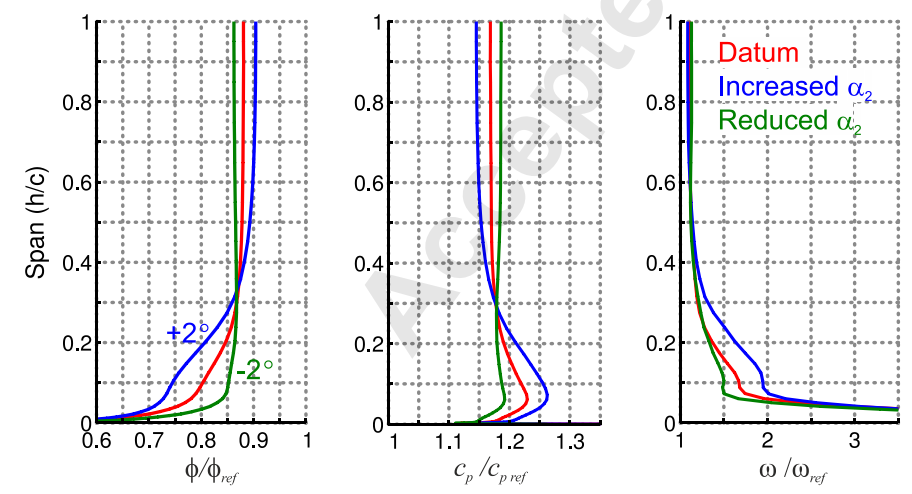

Figure 10 The effect of blade exit flow angle on the span wise distribution of $\varphi, \omega$ and local $c_{p}\left(\phi / \phi_{\text {ref }}=0.85\right)$
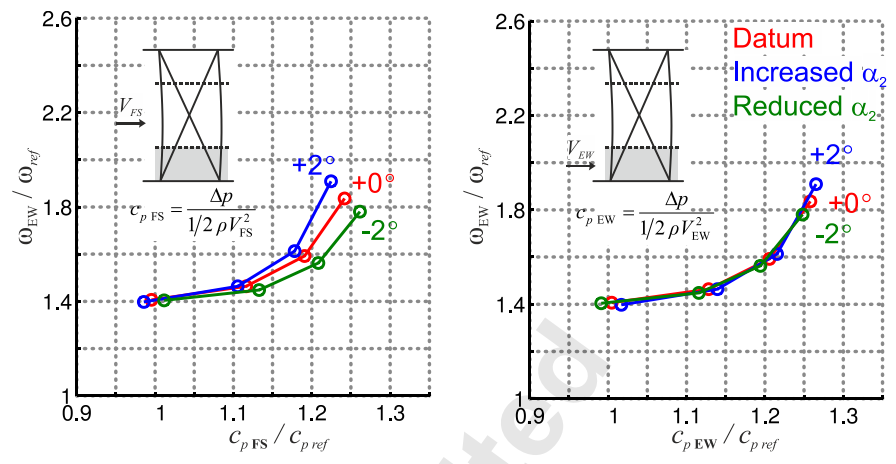

Figure 11 Endwall loss against pressure rise coefficient: LHS non-dimensionalised by freestream dynamic pressure, RHS non-dimensionalised by local endwall dynamic pressure.

dynamic pressure. The plots show that by basing the pressure rise coefficient on local dynamic pressure, a good collapse can be achieved. This was observed for all cases studied.

The effect of raising the endwall flow coefficient by reducing the blade exit flow can be seen by the circles on the RHS of Figure 11. As the flow coefficient increases, the dynamic pressure increases, reducing the local pressure rise coefficient and the endwall is driven down its loss characteristic. This is the key mechanism underpinning the design philosophy outlined in this paper. The spanwise distribution of loss and local pressure rise coefficient, as blade exit flow angle is changed, is shown in Figure 10.

The designer is now in a position to 'tailor' the endwall flow coefficient to increase endwall dynamic pressure, with the aim of rebalancing the range of the freestream and endwall regions on their respective loss characteristics.

\section{Practical Application}

The practical application of the new design philosophy will now be discussed. A practical design system should not try to undertake this process in one step but should allow useful parameters to be extracted from the multistage CFD and then fed back, iterating towards a final design. Two practical cases will be considered in this section: a case with low endwall loss and a case with high endwall loss, both shown in Figure 12.

First consider the low endwall loss case, LHS of Figure 12. The solid and dashed black lines represent freestream and endwall loss characteristics respectively. The red dots show the baseline design at two operating points, one at design and the other close to endwall failure. The first job for a designer is to decide how far they wish to move the endwall down its loss characteristic to balance endwall and freestream failure. In this case the blue points have been chosen. The designer would make the necessary changes to the blade angles at the design point, but concentrate on the movement along the characteristic at the off-design operating point. These changes are made at the expense of the freestream region which requires an opposite change in flow angle to maintain the overall design flow coefficient and pressure rise. This design process can in practice be done iteratively until the desired rebalance is achieved. 


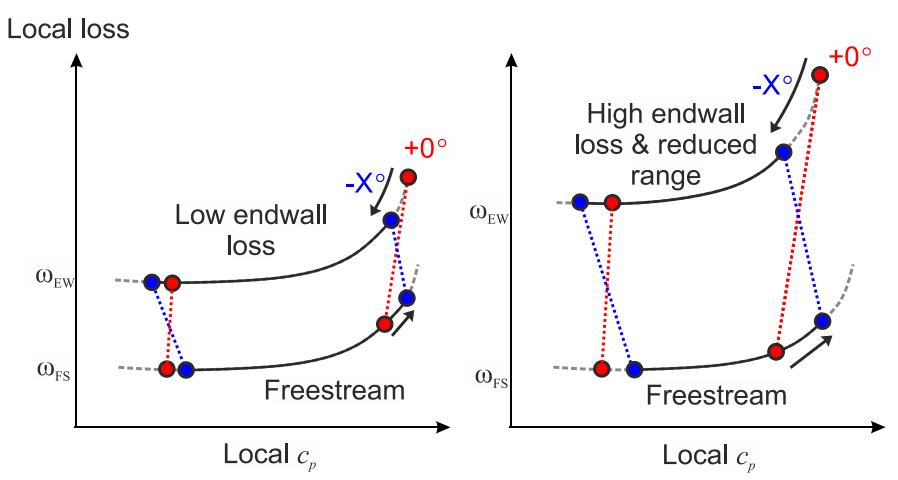

Figure 12 Schematic showing design procedure for blade rows with low and high endwall loss

Now let us consider the high loss endwall case, RHS of Figure 12. Such cases exist for endwalls with clearances i.e. real shrouds or cantilevers. This case has two main differences from the previous case. First the endwall loss and associated blockage is higher and second the endwall range, the pressure rise at which endwall loss rises rapidly, is lower.

Consider first the case of raising the endwall loss and blockage alone. Near the design point, this results in a larger difference in local flow coefficient between the endwall and freestream. To remove this effect requires a greater change in blade exit angle than was used in the low loss case.

Consider next the case of reduced endwall range. Because the endwall range is lower than for the low loss case, a larger increase in endwall flow coefficient will be required if the rebalance of the endwall and freestream range is to be achieved. This requires an even greater change in the blade exit angle.

In summary the size of the required exit flow angle change, which a designer should expect to introduce into an endwall region, depends on the ratio of endwall to freestream loss, and the ratio of the endwall to freestream operating range. However, as the endwall leakage gap increases, the two effects rise simultaneously resulting in a non-linear rise in the required change in blade exit metal angle.

\section{CASE STUDIES}

Three design case studies will now be presented: A compressor with an ideal shroud, a compressor with a real shroud, and a cantilevered compressor. All are conducted using the linear repeating stage methodology. The aim of the studies is to investigate whether the methodology of 'flipping' the

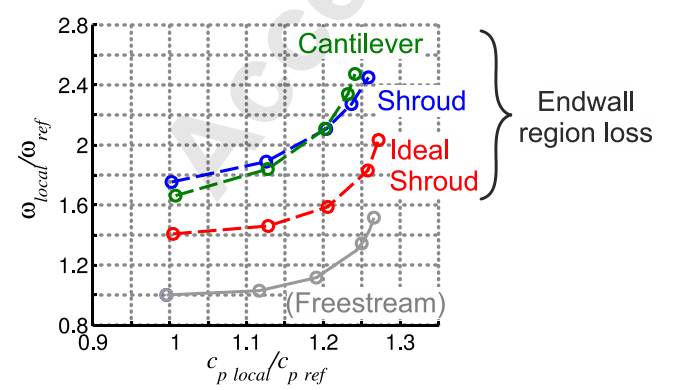

Figure 13 Loss characteristics of freestream and endwall regions for the three case studies. design process and introducing a reduced endwall trailing edge flow angle to tailor a more uniform inlet endwall region works for both shrouded and cantilevered compressors. This question is important because the endwall flow structures in cantilevered and shrouded compressors are very different.

Each design follows the same iterative procedure outlined in the previous section. The design aim in all cases is to balance the freestream and endwall operating range to maximise the compressor's overall operating range. The initial baseline cases all have a uniform spanwise trailing edge metal angle and have an optimised level of lean, based on studies of Gallimore et al. [1] and Taylor and Miller [2].

For the redesigned stages, changes to blade angle are made equally to both rotor and stator. The $3 \mathrm{D}$ lean of the redesigns is kept close to the baseline designs, with care taken not to introduce acute angles between endwall and blade suction surface, which could result from reducing blade exit angles near the endwall. The true chord at all spanwise locations for the redesigns is also maintained.

Before starting the three case studies it is worth comparing the freestream and endwall loss characteristics of the three cases. The endwall loss characteristics for the realistic cases, which introduce spanwise asymmetry, are an average of both hub and casing endwall regions. The characteristics given in Figure 13 show that the endwall regions for the real shroud and cantilever cases produce significantly more loss than the ideal shroud. This indicates that the real shroud and cantilever redesigns will require a larger change to trailing edge angle to ensure that the freestream and endwall ranges are balanced.

The two characteristic operating points used in the following discussion are the design conditions and the last stable converged operating point on the baseline case.

\section{Ideal shroud}

Rebalancing of the freestream and endwall operating range was undertaken at an off-design flow coefficient $\phi / \phi_{\text {ref }}=0.76$, which is the last stable converged condition for the baseline design. The LHS of Figure 14 shows the spanwise distribution of flow coefficient and the stator exit loss contours, at $\phi / \phi_{\text {ref }}$ $=0.77$. The redesign has successfully achieved a significantly more uniform flow coefficient across the span. This has resulted in the stator wake being more uniform across the span
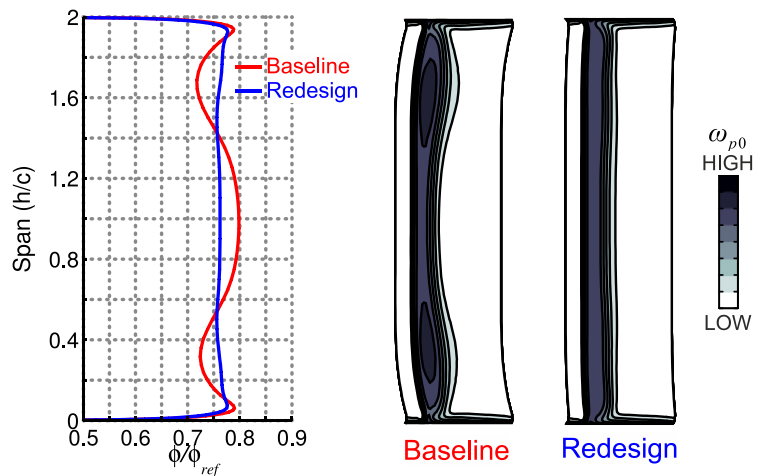

Figure 14 Spanwise distribution of flow coefficient at stator inlet and stator exit wake loss $\left(\phi / \phi_{\text {ref }}=0.77\right.$, ideal shroud $)$ 

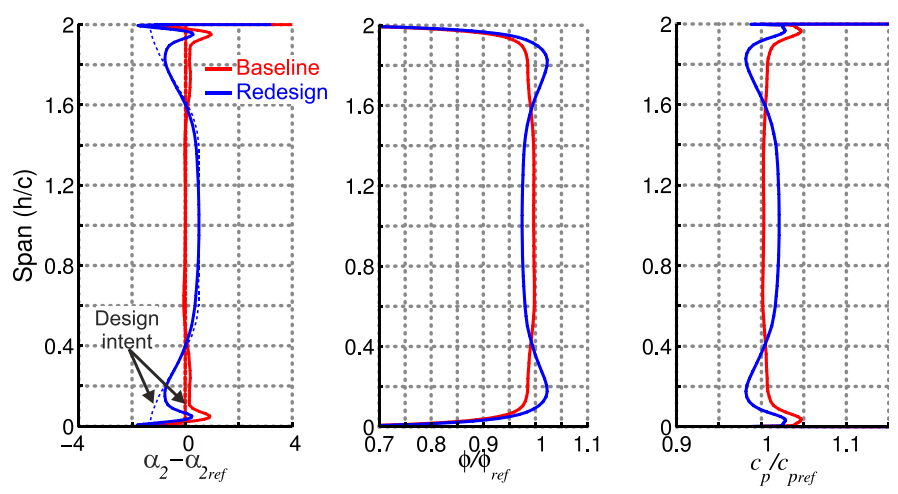

Figure 15 Spanwise distribution of stator exit flow angle, rotor inlet flow coefficient and rotor $c_{p}\left(\phi / \phi_{\text {ref }}=1.0\right.$, ideal shroud $)$

and very little evidence of corner separations.

The LHS of Figure 15 shows the change in design intent blade exit flow angle (dashed line) and the real exit flow angle (solid line) for the stator (which is identical to the rotor). Close to the endwalls the blade exit flow angle has been reduced by $1.3^{\circ}$, while close to mid-span it has been raised by $0.5^{\circ}$. A Gaussian distribution of flow angle between the endwall and freestream was found to be most effective, and is used in all cases. The centre of Figure 15 shows the effect of the redesign on the local flow coefficient at the design operating point. At this condition the stage inlet endwall flow region has been designed to have a higher dynamic pressure than the freestream. The desired outcome of achieving a lower local pressure rise coefficient near the endwall is shown on the RHS.

Figure 16 shows that the difference between the endwall and freestream loss is relatively small, therefore only a small movement in the two characteristics is required to rebalance the freestream and endwall regions. This means that for an ideal shroud the redesign can only achieve a small increase in operating range. In this case $8 \%$.

\section{Real shroud}

The real shroud has a leakage gap of $1 \%$ chord. Rebalancing of the freestream and endwall operating range was undertaken at an off-design flow coefficient $\phi / \phi_{\text {ref }}=0.76$. The LHS of Figure 17 shows the spanwise distribution of flow coefficient and the RHS the stator exit loss contours, at $\phi / \phi_{\text {ref }}$ $=0.79$. The figure shows that the redesign has once again
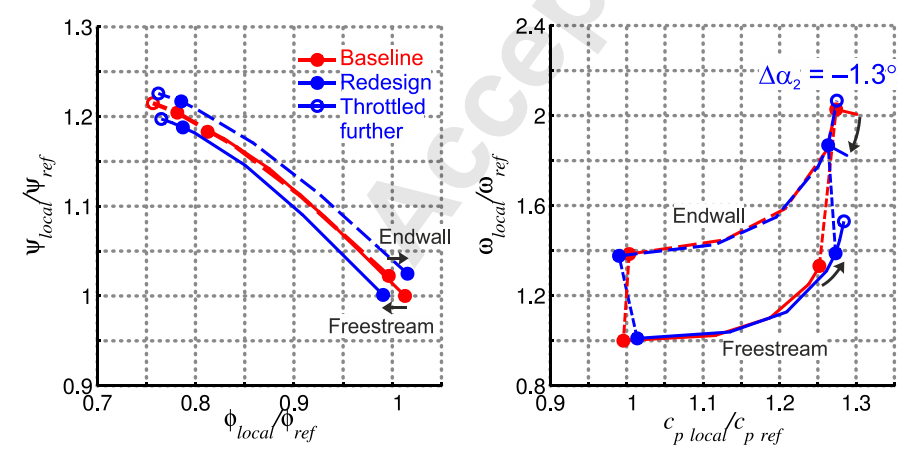

Figure 16 LHS: Loading characterisitics, RHS: loss characteristics of baseline design and redesign (Ideal shroud)
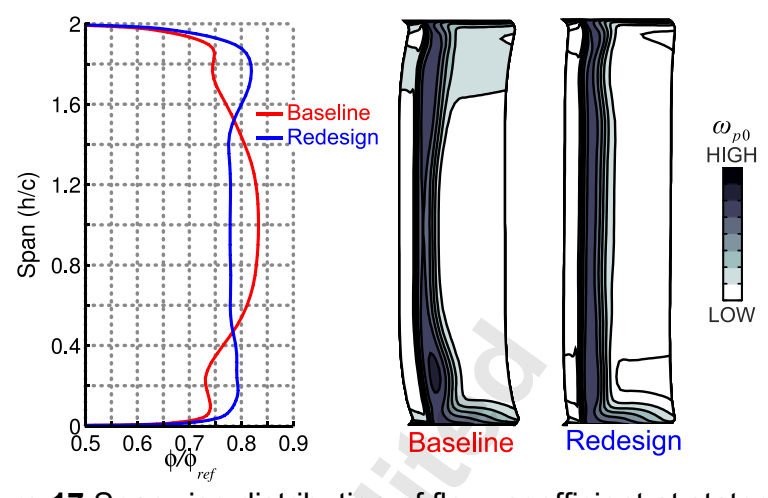

Figure 17 Spanwise distribution of flow coefficient at stator inlet and stator exit wake loss ( $\phi / \phi_{\text {ref }}=0.79$, Real shroud)

successfully achieved a significantly more uniform flow coefficient across the span, delivering a higher dynamic pressure into the endwall region. This again results in the stator wake being more uniform across the span with very little evidence of corner separations. Close to the hub endwall the leakage flow remains unchanged.

Close to the endwalls the blade exit flow angle has been reduced by $2.5^{\circ}$, while close to mid-span it has been raised by $1.1^{\circ}$. This is about twice the change in exit flow angle that was required for the ideal shroud. The reason for the increased angle change can be seen in Figure 18. Because the real shroud has a higher endwall loss (and resulting blockage) than the ideal shroud case, the imbalance between freestream and endwall local pressure rise coefficient for the baseline design is greater. To balance endwall and freestream failure, therefore required greater movement of the endwall and freestream characteristics. This greater imbalance resulted in a larger range improvement over the baseline design of $16 \%$.

\section{Cantilever}

The cantilever case has a leakage gap of $1 \%$ chord. Rebalancing of the freestream and endwall operating range was undertaken at an off-design flow coefficient $\phi / \phi_{\text {ref }}=0.76$. The LHS of Figure 19 shows the spanwise distribution of flow coefficient and the stator exit loss contours, at $\phi / \phi_{\text {ref }}=0.81$. The redesign can be seen to make the flow more uniform across the span, however, it is not as uniform as in the shrouded cases. This is because the leakage jet makes it more difficult to iterate
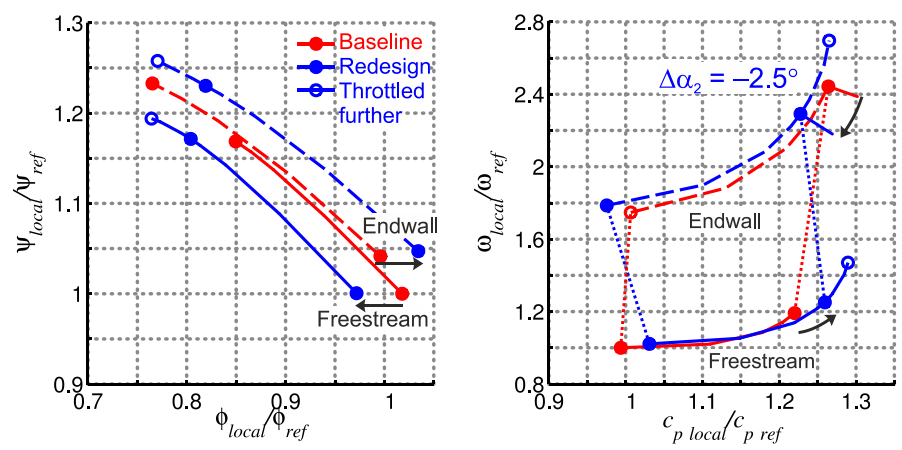

Figure 18 Loading characterisitics, RHS: loss characteristics of baseline design and redesign (Real shroud) 

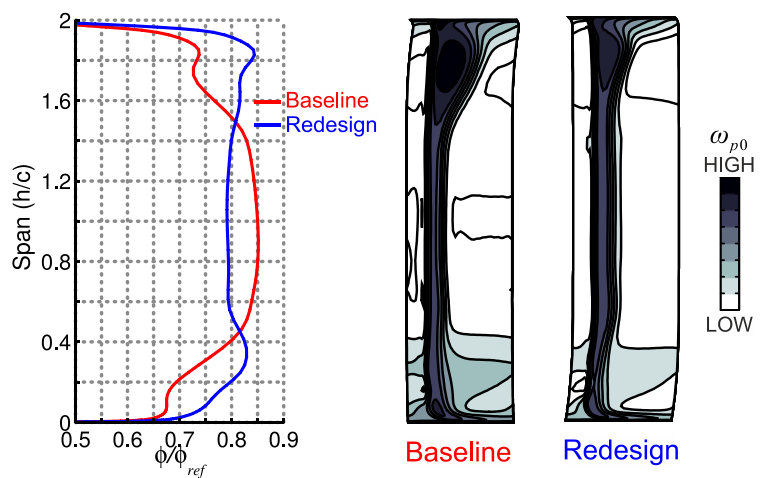

Figure 19 Spanwise distribution of flow coefficient at stator inlet and stator exit wake loss $\left(\phi / \phi_{\text {ref }}=0.81\right.$, Cantilever $)$

towards a completely uniform profile. It is thought that by employing an optimiser an even better spanwise uniformity could be easily achieved.

Close to the endwalls the blade exit flow angle has been reduced by $3.5^{\circ}$, while close to mid-span it has been raised by $1.3^{\circ}$. This is even larger than in the real shroud case. The reason for the increased angle change can be seen in Figure 20. This resulted in a larger range improvement over the baseline design of $22 \%$.

Of all the baseline designs examined in this study, the cantilevered case has the lowest operating range. However, as shown in Figure 21, the cantilever redesign is able to restore the range to the same level achieved by the redesigns for the other cases.

It is interesting to note that the methodology described in this paper works equally well for both shrouded and cantilevered compressors. This at first appears surprising with the endwall flow structures of a shrouded and cantilever compressor being very different. However, the methodology simply relies on the ratio of endwall to freestream loss and ratio of endwall to freestream operating range. The method therefore works equally well on any endwall configuration.

It should be noted that the failure modes in the baseline and redesign cases, of all three compressor endwall types (ideal and real shroud and cantilever) are unchanged. The redesign simply rebalances the freestream and endwall regions on their respective loss characteristics so that the compressor range is
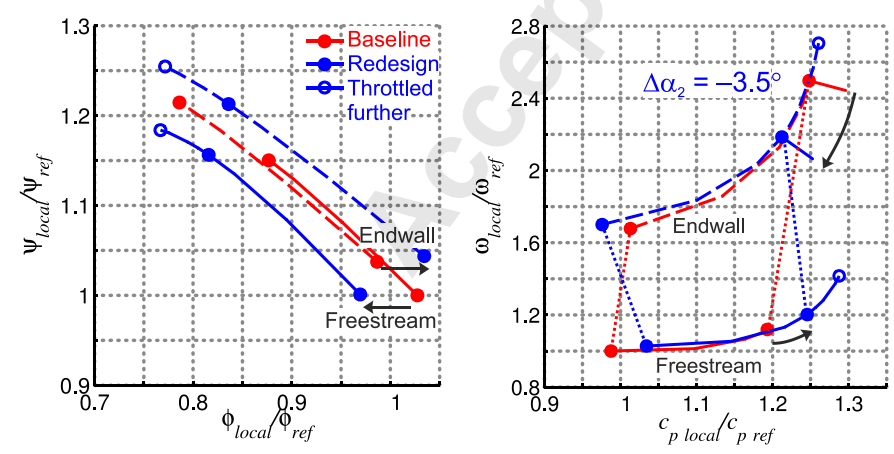

Figure 20 LHS: Loading characterisitics, RHS: loss characteristics of baseline design and redesign (Cantilever)
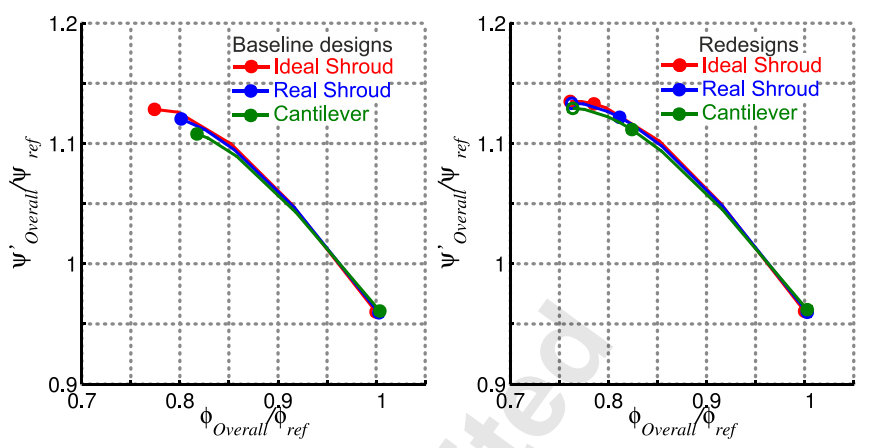

Figure 21 Comparison of operating range for all cases studies: LHS: Baseline designs, RHS: Redesigns

maximised.

\section{Improving design efficiency}

Up to this point in the paper the new design philosophy has been used to increase the compressor's operating range. The method, however, also changes design loss. Because more mass is passed through the endwall region the design efficiency for the cantilever case drops by $\sim 0.1 \%$. This penalty is smaller for the shroud and ideal shroud case, as the magnitude of the design changes is smaller.

If instead of increasing operating range a designer decided to maintain operating range and improve design efficiency then this can be achieved by removing blades. Figure 22 shows a second cantilever redesign in which blades have been removed. In this case the blade count was systematically reduced and at each point a redesign was undertaken. The design pressure rise and flow was maintained. The operating range was judged against an aerodynamic throttle characteristic. The optimal stage has $15 \%$ of blades removed reducing profile loss by $12 \%$. The overall improvement in design efficiency was $0.5 \%$.

\section{Real case study}

The case studies shown earlier in the paper were all undertaken using the linear repeating stage methodology. This

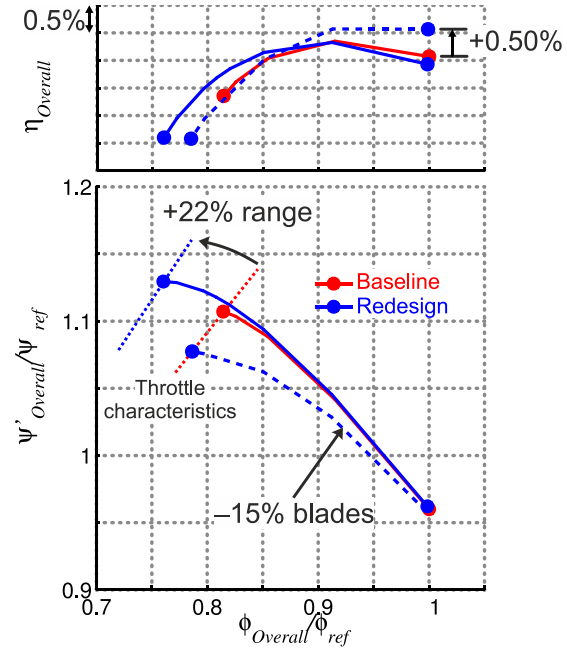

Figure 22 Effect of new design method on overall operating range and design point efficiency (Cantilever) 

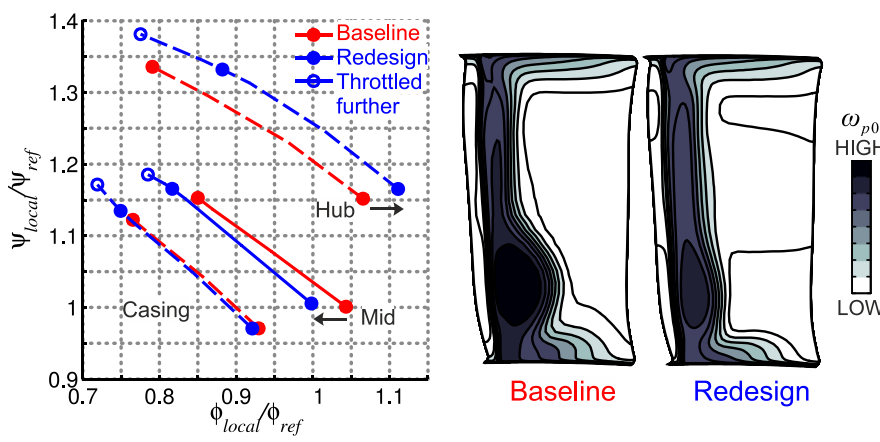

Figure 23 LHS: Loading characteristics and RSH: stator exit loss contours at $\phi / \phi_{\text {ref }}=0.79$, for SMURF baseline and redesigns

involves symmetrical endwalls and a hub to tip ratio of one. It is therefore worthwhile to present a redesign of the SMURF three stage compressor shown earlier in the paper. The redesign was undertaken using the same design philosophy as previously discussed. The major difference for the SMURF compressor is that due to the lower hub to tip ratio, the hub and casing velocity triangles vary across the span. The stage operating range is limited by a hub separation in the stator. The required redesign therefore needs to be asymmetric between hub and casing.

The level of asymmetry between hub and casing regions in the redesign of the SMURF compressor is shown by the different amount of movement in loading characteristics on the LHS of Figure 23. The improvement in operating range was predicted to be $\sim 20 \%$. Loss contours at stator 3 exit are shown on the RHS of Figure 23 at a flow coefficient of $\phi / \phi_{\text {ref }}=0.79$, close to the operating limit of the baseline SMURF design. The reduction in the hub corner separation in the redesign illustrates the improved stability that has resulted from reducing the local pressure rise coefficient in the stator hub.

\section{UNDERLYING MECHANISM}

Finally it is worth discussing the underlying mechanism on which the new design philosophy is based. Koch [15] concisely sums up current thinking on the effect of the velocity triangles on a compressor's operating range. He notes that a stage's velocity triangle design has an 'unexpectedly large' effect on its maximum pressure rise. He says that because all of the streamlines in a stage pass through essentially the same pressure rise, the maximum pressure rise that can be achieved is limited by the dynamic pressure of the endwall boundary layer fluid from the preceding blade row. The link between the design velocity triangle and the maximum pressure is that the design velocity triangle determines the dynamic pressure of the endwall boundary layer fluid relative to the freestream. The findings of this paper fit with this conventional wisdom. By raising the flow coefficient in the endwall region the designer raises the endwall dynamic pressure relative to the freestream and thus raises the compressor's operating range.

There is, however, a key contradiction between the current work and Koch [15], which warrants further investigation. Koch shows that the endwall dynamic pressure can be increased by designing a stage with lower design flow coefficient and high stagger. This seems to contradict the work in this paper which shows that the endwall dynamic pressure can be increased by designing a stage which has a higher endwall design flow coefficient.

To understand the reason for this apparent contradiction it is important to first understand the work on which Koch [15] is based. Work by Smith [16] and Ashby [17] showed that in a rotating machine the change of reference frame acts to 'reenergise' the endwall dynamic pressure deficit passing into the downstream blade row. This boundary layer re-energisation is unique to rotating machines and does not appear in conventional diffusers. Smith and Ashby also showed that the magnitude of this re-energisation depends on the included angle of $\alpha_{1}+\beta_{2}$ (or $\alpha_{2}+\beta_{1}$ ) in the design velocity triangle. The reason for this can be seen in the central plot of Figure 24. The figure shows that the endwall boundary layer flow leaving the upstream blade row, in this case a rotor, is presumed to flow at the same relative angle as the free stream fluid, and the minimum absolute velocity entering the downstream blade row will be $V_{\text {min }}$. Furthermore, it is seen that if the included angle between the relative and absolute free stream vectors, $\alpha_{1}+\beta_{2}$ is less than $90^{\circ}, V_{\min }$ will be less than $V$.

The ratio of the minimum endwall dynamic pressure to freestream dynamic pressure, $V_{\min }^{2} / V^{2}$, determines the 'effective dynamic pressure factor', F, named by Koch because it is the number by which the free stream is multiplied to give the effective dynamic pressure entering a blade row. Koch shows that the closer $\alpha_{1}+\beta_{2}$ is to $90^{\circ}$ the higher the endwall dynamic pressure becomes, increasing the effective dynamic pressure factor and hence increasing the maximum pressure rise capability of the stage. He shows that to achieve this, a stage should be designed with a low design flow coefficient and high stagger.

The design philosophy described in this paper raises the 'effective dynamic pressure factor' while keeping the overall design flow coefficient constant. This can be understood by considering the RHS of Figure 24. In the endwall region the rotor blade exit flow angle, $\beta_{2}$, is reduced and for repeating stages, as shown earlier in the paper, the flow coefficient in the endwall region increases, whilst the loading remains fixed. This redesigned endwall region in the figure is shown in red and it shows that the reduced endwall exit angle has the effect of raising $V_{\min }$. To aid clarity in the figure, the freestream flow coefficient in this redesign has been left unchanged. In practice, for a high aspect ratio design, the freestream $V$ would remain relatively unchanged while for a low aspect ratio stage it would have to drop more to maintain the overall flow coefficient. Either way the 'effective dynamic pressure factor' rises.

A comparison of the work of Koch [15] and the current work is shown in Figure 25. The red line shows how changing the design flow coefficient of a conventionally designed stage raises the effective dynamic pressure factor. The blue line shows how tailoring the endwall exit flow angle, $\Delta \alpha_{2(\mathrm{EW})}$, using the new design philosophy also increases the effective dynamic 


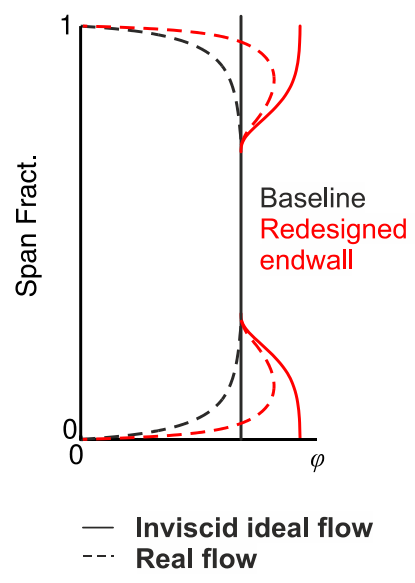

Figure 24 Influence of local endwall velocity triangle design on the 'effective dynamic pressure factor', F. LHS: Radial profiles. Centre: Baseline velocity triangle (adapted from Koch [15] and Smith [18]), RHS: Endwall redesign velocity triangle

pressure factor. In this case, the extra degree of freedom provided by the new design philosophy allows any flow coefficient design to have an increased dynamic pressure factor. This shows that when 'tailoring' the endwall velocity triangle the designer should be careful not to follow the conventional wisdom of raising $\alpha_{1}+\beta_{2}$, but instead should think directly about the consequence of the design change on the 'effective dynamic pressure factor'.

\section{Experimental Validation}

It is now important to experimentally validate the underlying mechanism on which this paper is based. To do this an experiment is required which re-designs the rotor endwall velocity triangle in a similar way to that shown in Figure 24, and determines the impact on the 'effective dynamic pressure factor' and on the downstream stator on which the re-energised endwall boundary layer impinges. In designing this experiment it is important to leave the rotor inlet boundary condition and the downstream stator design unchanged.

The experiments were undertaken on the Gibbons single

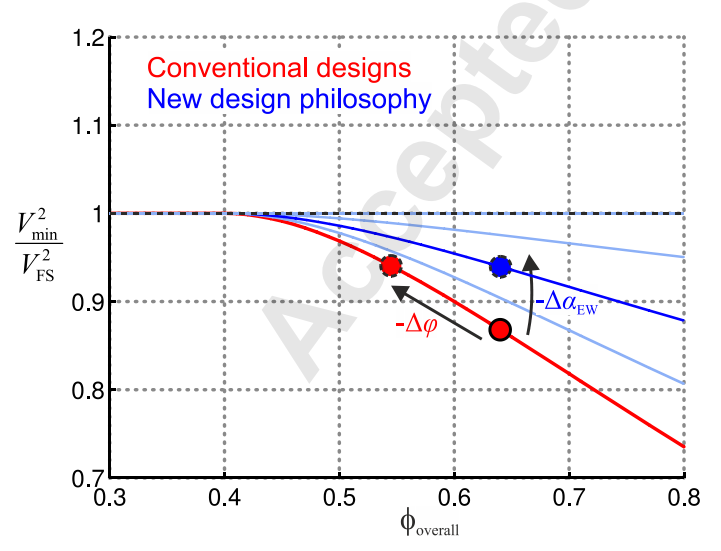

Figure 25 Conventional and new method for increasing the 'effective dynamic pressure factor' stage compressor. As the stage is throttled the stator fails due to the rapid expansion of a 3D separation near the hub endwall. The baseline rotor has a conventional exit flow angle distribution, $\beta_{2}$, across the span intended to produce a flat flow coefficient profile. The redesign uses the new design philosophy outlined earlier in the paper. In the hub endwall region $\beta_{2}$ was reduced on average by $3^{\circ}$, and raised in the mid and casing region by $\sim 1.5^{\circ}$ to maintain the same overall flow coefficient and pressure rise. The experimental spanwise flow coefficient distribution at rotor exit is shown on the LHS of Figure 26. The dynamic pressure in the stator relative frame is also shown. The redesign aimed to increase the hub 'effective dynamic pressure factor' by $15 \%$. It can be seen that this design intent level of hub endwall re-energisation has been achieved.

The effect of changing the 'effective dynamic pressure factor' on the downstream stator can be seen on the exit loss contours in Figure 26. The condition shown is at a $\phi / \phi_{\text {ref }}=$ 0.85 , close to the baseline stage's maximum pressure rise. The effect of re-energising the rotor exit endwall flow on the stator can also be seen in Figure 26. The hub corner separation in the redesigned stage has been reduced in size significantly.

The underlying mechanism in this paper is the reenergisation of the endwall flow by designing an increased flow coefficient in the endwall region. This should be seen as additive to the re-energising effect provided by the change in reference frame, explained by Koch [15]. For very low flow coefficient designs, where the included angle is greater than $90^{\circ}$, the endwall boundary layer dynamic pressure is reenergised beyond that of the freestream, therefore additional reenergisation may not be required. However, at more optimal points on the compressor Smith Chart, such as medium to high flow coefficients, the extra re-energisation becomes very useful. More importantly the new mechanism unlocks the link between a stage's maximum pressure rise and its design flow coefficient. This allows designers to design compressors at any flow 

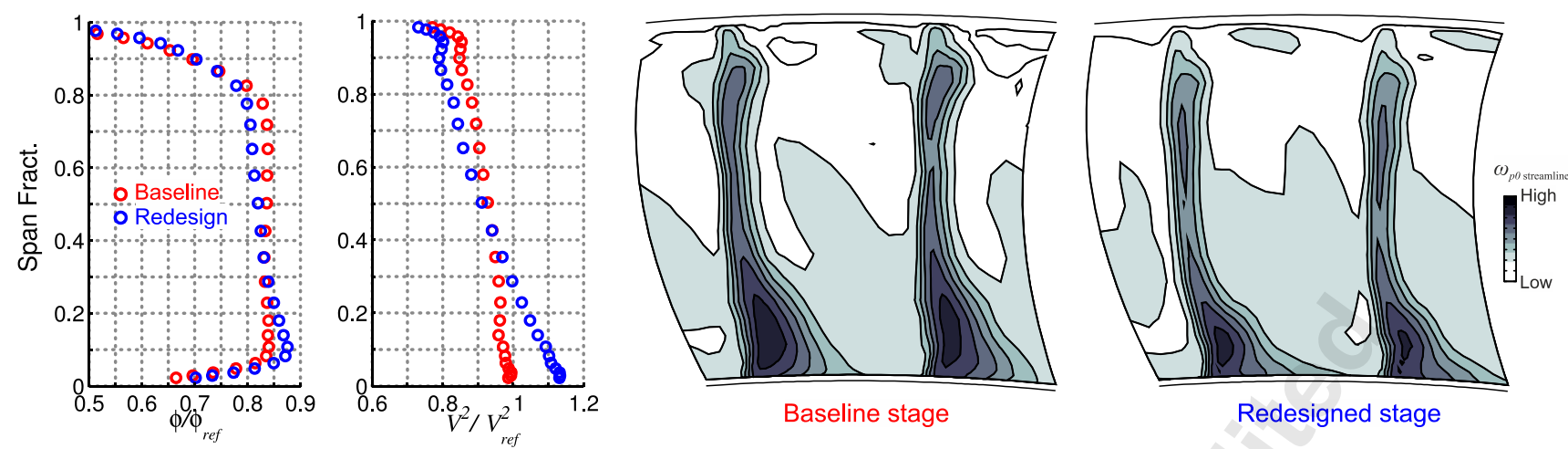

Figure 26 Demonstration of endwall re-enrgisation by endwall redsign.

LHS rotor exit traverse profile. RHS stator exit loss contours, $\phi / \phi_{\text {ref }}=0.85$

coefficient whilst still being able to achieve a high maximum pressure rise.

\section{CONCLUSIONS}

Koch [15] demonstrated a strong link between a compressor's flow coefficient and stagger, and its maximum pressure rise. The underlying mechanism responsible for this effect is the re-energisation of the endwall boundary layer due to the frame of reference change between blade rows. This results in designs with a low flow coefficient having a high maximum pressure rise. This paper presents an addition mechanism for re-energising the endwall boundary layer, known as 'high flow endwalls'. It has been shown that this mechanism can be used to break the link between the design flow coefficient of a compressor and its maximum pressure rise allowing compressors of medium and high design flow coefficient to be designed with a high maximum pressure rise.

The new design philosophy also implies that current design methods limit a designer's ability to achieve the optimal design. In a traditional compressor design method, a through-flow model is used to fix the inter blade radial profiles. This allows extensive rig and engine experience to be introduced into the design process and prevents stage matching errors being introduced due to inaccuracies in the CFD. This paper shows that although such design methods have the advantage of accurately predicting stage matching they stop the designer from achieving the true optimum design, in terms of both operating range and design efficiency.

This paper shows the design process should be 'flipped'. Designing in the true multistage environment allows the endwall of each blade row to be designed, not to improve the particular blade row that is being designed, but to increase the dynamic pressure in the inlet endwall regions of downstream blade rows.

This paper shows that trying to reduce the pressure rise experienced by an endwall in a multistage environment is not a practical design target. Instead designers should concentrate on lowering the local endwall static pressure rise coefficient by increasing the endwall dynamic pressure.

The method outlined in this paper has been shown to work on all endwall types. The magnitude of the decrease in endwall trailing edge flow angle depends on the ratio of endwall to freestream loss and the ratio of endwall to freestream operating range. In a cantilevered compressor the new design method can either be used to increase operating range by $\sim 20 \%$ or increase efficiency by $\sim 0.5 \%$.

Incorporating the new philosophy into the current design systems could be achieved by the designers undertaking multistage CFD at a much earlier stage in the design process. The designer should use the multistage CFD to tailor the radial profiles throughout the compressor. The tailored radial profiles can then be transferred back into through-flow design methods. The aim would be to allow the designer the extra degree of freedom required to tailor the radial profiles while retaining the ability of the design system to learn from extensive rig experience. If the design system was altered in such a way then the blockage and deviation models in the though-flow would of course have to be extended to ensure their accuracy in this new area of the design space were maintained. This could be achieved by undertaking a range of new multistage low speed tests.

\section{ACKNOWLEDGMENTS}

The authors would like to thank Rolls-Royce plc for their permission to publish this work, James Taylor for his generous help with both computational and experimental methods; Chris Hall, Tony Rae; Nick Cumpsty, Simon Gallimore \& John Adamczyk for their many discussions, and finally Bronwyn Power and the reviewers for their suggestions on improving this paper. This research was funded by the EU 7th Framework Programme, as part of LEMCOTEC project, under Grant Agreement 283216.

\section{NOMENCLATURE}

$$
\begin{aligned}
& c=\text { chord } \\
& h=\text { blade height } \\
& \alpha=\text { absolute tangential flow angle } \\
& \beta=\text { relative tangential flow angle } \\
& p=\text { pressure } \\
& \rho=\text { density } \\
& T=\text { temperature } \\
& U=\text { mid-height blade speed } \\
& v_{x}=\text { axial velocity }
\end{aligned}
$$


$V=$ relative total velocity

$\phi=$ flow coefficient $\left(v_{x} / U\right)$

$\Delta h_{0}=$ change in specific stagnation enthalpy

$\psi=$ loading $\left(\Delta h_{0} / U^{2}\right)$

$\psi^{\prime}=$ stagnation pressure rise coefficient $\left(\Delta p_{0} / \rho U^{2}\right)$

$c_{p}=$ local static pressure rise coefficient $\left(\Delta p / 0.5 \rho V^{2}\right)$

$\Delta s=$ change in specific entropy

$\omega=$ entropy loss coefficient $\left(T_{0} \Delta s / 0.5 V^{2}\right)$

$\omega_{p 0}=$ pressure loss coefficient $\left(\overline{P_{01}}-P_{02}\right) /\left(\overline{P_{01}}-\overline{P_{1}}\right)$

$\eta=$ isentropic efficiency

Subscripts

$f s=$ freestream

ew $=$ endwall

$1=$ blade row inlet

$2=$ blade row exit

$0=$ stagnation quantity

ref $=$ design point freestream reference (for plots with more than one case, this is the baseline case. Exception: $\varphi_{\text {ref }}$ uses the overall baseline design point $\varphi$ )

\section{REFERENCES}

[1] Gallimore, S. J., Bolger, J. J., Cumpsty, N. A., Taylor, M. J., Wright, P. I., and Place, J. M. M., 2002, "The Use of Sweep and Dihedral in Multistage Axial Flow Compressor Blading---Part I: University Research and Methods Development," Journal of Turbomachinery, 124(4), pp. 521-532.

[2] Taylor, J. V., and Miller, R. J., 2015, "Competing 3D Mechanisms in 3D Flows," Proc. ASME Turbo Expo, Montreal.

[3] Holloway, P. R., Knight, G. L., Koch, C. C., and Shaffer, S. J., 1982, "Energy Efficient Engine High Pressure Compressor Detail Design Report," No. CR-165558, NASA.

[4] Wisler, D. C., 1985, "Loss Reduction in Axial-Flow Compressors Through Low-Speed Model Testing," Journal of Engineering for Gas Turbines and Power, 107(2), pp. 354-363.

[5] Vasudevan Kanjirakkad, Antoine Goddard, Howard Hodson, and Longley, J., 2010, "SMURF Research Compressor Report: Build-1 Experimentation," Whittle Laboratory, University of Cambridge,.

[6] Moinier, P., and Giles, M. B., 1998, "Preconditioned Euler and Navier-Stokes calculations on unstructured grids," Proc. 6th ICFD Conference on Numerical Methods for Fluid Dynamics, Oxford, UK.

[7] Menter, F. R., 1992, "Improved Two-Equation k-omega Turbulence Models for Aerodynamic Flows," NASA STI/Recon Technical Report N, 93, p. 22809.

[8] Shahpar, S., and Lapworth, L., 2003, "PADRAM: parametric design and rapid meshing system for turbomachinery optimisation."

[9] McKenzie, A. B., 1997, Axial Flow Fans and Compressors, Ashgate Publishing Limited.

[10] To, H.-O., and Miller, R. J., 2015, "The Effect of Aspect Ratio on Compressor Performance," Proc. ASME Turbo Expo, Montreal.
[11] Smith, L. H., 1970, "Casing Boundary Layers in Multistage Axial Flow Compressors," Flow Research on Blading, Vol. 106, pp. 635-647.

[12] Goodhand, M. N., and Miller, R. J., 2012, "The Impact of Real Geometries on Three-Dimensional Separations in Compressors," Journal of Turbomachinery, 134(2), p. 021007.

[13] Wadia, A. R., and Beacher, B. F., 1990, "ThreeDimensional Relief in Turbomachinery Blading," Journal of Turbomachinery, 112(4), pp. 587-596.

[14] Cumpsty, N. A., 1990, "Discussion: Three-Dimensional Relief in Turbomachinery Blading," Journal of Turbomachinery, 112(4), pp. 587-596.

[15] Koch, C. C., 1981, "Stalling Pressure Rise Capability of Axial Flow Compressor Stages," Journal of Engineering for Power, 103(4), pp. 645-656.

[16] Smith, L. H., Jr. , 1958, "Recovery Ratio - A Measure of the Loss Recovery Potential of Compressor Stages," Trans. ASME, 80, pp. 517-524.

[17] Ashby, G. C., Jr, 1957, "Investigation of the effect of velocity diagram on inlet total-pressure distortions through single-stage subsonic axial-flow compressors," NACA Research Memorandum.

[18] Smith, J. L. H., 2002, "Axial Compressor Aerodesign Evolution at General Electric," Journal of Turbomachinery, 124(3), pp. 321-330. 